\title{
The Current Status of the Production and Supply of Gallium-68
}

\author{
Krishan Kumar
}

\begin{abstract}
Gallium-68 $\left({ }^{68} \mathrm{Ga}\right)$ is an important radionuclide due to its successful use in the clinic. Currently, ${ }^{68} \mathrm{Ga}$ is produced and supplied by using germanium-68/Gallium-68 $\left({ }^{68} \mathrm{Ge} /{ }^{68} \mathrm{Ga}\right)$ generator systems in the preclinical and clinical environments. Until recently, the supply of ${ }^{68} \mathrm{Ge} /{ }^{68} \mathrm{Ga}$ generators, specifically the good manufacturing practices (GMP) grade, had a long lead time (up to 18 months). This led researchers to investigate the cyclotron production of ${ }^{68} \mathrm{Ga}$ by using solid and liquid targets. This report summarizes an overview of the chemistry, coordination chemistry, and radiochemistry of Ga and the current status of manufacturing and supply of ${ }^{68} \mathrm{Ga}$ radionuclide.
\end{abstract}

Keywords: ${ }^{68} \mathrm{Ga},{ }^{68} \mathrm{Ge} /{ }^{68} \mathrm{Ga}$ generators, cyclotron produced ${ }^{68} \mathrm{Ga}$, liquid targets, production and supply, solid targets

$\mathbf{T}$ he interest in Gallium-68 $\left({ }^{68} \mathrm{Ga}\right)$ has increased tremendously in the recent past due to (1) it becoming a routinely used radioisotope in clinical positron emission tomography (PET) imaging facilities around the world, and (2) its coordination chemistry applies to the development of ${ }^{177} \mathrm{Lu}$-labeled theranostic agents. For example, ${ }^{68} \mathrm{Ga}$-labeled somatostatin receptor-specific peptides, DOTA-TATE (NETSPOT) and DOTA-TOC in the United States and DOTA-TOC (SomaKit) in the European Union, are being used successfully for neuroendocrine tumor imaging. In addition, worldwide clinical trials with ${ }^{68} \mathrm{Ga}$-labeled ProstateSpecific Membrane Antigen (PSMA) target-specific ligands, PSMA-11 and PSMA-617, are ongoing for prostate cancer imaging. ${ }^{1,2}$ The objective of the present report is to summarize the background and the current status of the production and supply of ${ }^{68} \mathrm{Ga}$.

As a history and background, Mendeleev, in 1871, predicted an unknown element, eka-aluminum, in his periodic table and believed that it would be directly below aluminum with 68 atomic mass. ${ }^{3}$ Four years later, Boisbaudran discovered $\mathrm{Ga}$ element from the observation of two violet lines in the spectrum of a material separated from zinc blend. ${ }^{4} \mathrm{Ga}$ was named from the Latin word Gallia for Gaul, the native place of Boisbaudran in France. Electropositive Ga, with the most common and stable oxidation state of +3, 47-62 pm ionic radius, and sluggish water-exchange rate, belongs to group 13 of the periodic table of the elements. Due to high charge density, $\mathrm{Ga}^{3+}$ is highly acidic with a $\mathrm{pK}_{\mathrm{a}}$ of 2.6 and is easily hydrolyzed to $\mathrm{Ga}(\mathrm{OH})_{n}$ (where $n=1-4$ ) under even acidic conditions. All of the hydrolyzed species, except $\mathrm{Ga}(\mathrm{OH})_{4}{ }^{-}$, are insoluble in the aqueous medium. Due to the strong affinity of $\mathrm{Ga}^{3+}$ for hydroxide, it tends to demetallate from its complexes to form soluble $\mathrm{Ga}(\mathrm{OH})_{4}{ }^{-}$and has a strong binding affinity toward transferrin. ${ }^{5}$

The design of a Ga-based imaging pharmaceutical involves using a bifunctional chelating agent that (1) is capable of keeping the metal bound to a chelator in the in vivo environment, and (2) conjugates to a receptor-specific biomolecule. Generally, acyclic (HBED-CC)* and macrocyclic polyaminocarboxylates (NOTA and DOTA)* chelating agents have been found to form thermodynamically stable and kinetically inert metal chelates. ${ }^{5}$ These properties led to the development of ${ }^{68} \mathrm{Ga}$-labeled DOTA-TATE, DOTATOC, PSMA-11, and PSMA-617 as commercial and potential PET imaging pharmaceuticals, respectively.

Ga has two naturally occurring stable isotopes, ${ }^{69} \mathrm{Ga}$ and ${ }^{71} \mathrm{Ga}$, with $60.11 \%$ and $39.89 \%$ natural abundance, respectively. Three $\mathrm{Ga}$ radionuclides are available for the

*HBED-CC is N,N'-bis [2-hydroxy-5-(carboxyethyl) benzyl] ethylenediamine- $\mathrm{N}, \mathrm{N}^{\prime}$-diacetic acid, NOTA is 1,4,7triazacyclononane-1,4,7-triacetic acid, and DOTA is 1,4,7,10tetraazacyclododecane-1,4,7,10-tetraacetic acid.

Laboratory for Translational Research in Imaging Pharmaceuticals, Department of Radiology, The Wright Center of Innovation in Biomedical Imaging, The Ohio State University, Columbus, Ohio.

Address correspondence to: Krishan Kumar; Laboratory for Translational Research in Imaging Pharmaceuticals, Department of Radiology, The Wright Center of Innovation in Biomedical Imaging, The Ohio State University; Columbus, OH 43212 E-mail: kumar@wcibmi.org 
radiolabeling of biomolecules as potential imaging pharmaceuticals. ${ }^{66} \mathrm{Ga}\left(t_{1 / 2}=9.49 \mathrm{~h}, \beta^{+} 56.5 \%, \mathrm{E}_{\beta+, \max } 4.15\right.$ $\mathrm{MeV}$; electron capture [EC] $43.5 \%, \mathrm{E}_{\gamma}, \max 4.0 \mathrm{MeV}$ ) and ${ }^{68} \mathrm{Ga}\left(t_{1 / 2}=67.71 \mathrm{~min}, \beta^{+} 89 \%, \mathrm{E}_{\beta+, \max } 1.9 \mathrm{MeV}\right.$; EC $11 \%, \mathrm{E}_{\gamma} \max 4.0 \mathrm{MeV}$ ) decay by positron emission and consequently are suitable for PET imaging. ${ }^{67} \mathrm{Ga}\left(t_{1 / 2}=\right.$ $78.3 \mathrm{~h}, \gamma 37 \%, 93.3 \mathrm{keV} ; \gamma 24.4 \%, 184.6 \mathrm{keV}, \gamma 16.6 \%$, $300.2 \mathrm{keV}$ ) decays by gamma-emission and is used as a SPECT (single-photon emission computed tomography) imaging agent. ${ }^{66} \mathrm{Ga}$ is an attractive radionuclide, due to its longer half-life than ${ }^{68} \mathrm{Ga}$, for evaluation of biomolecules with slow clearance rate as imaging pharmaceuticals; however, limited research is conducted related to its production and use as a potential PET imaging pharmaceutical. ${ }^{6}$ This is due to its high positron energy, which lowers the resolution of images and has the potential to give high radiation dose to patients as it emits multiple $\gamma$ rays with energies above $1 \mathrm{MeV} .{ }^{68} \mathrm{Ga}$ radioisotope is a pure orbital EC decay product of germanium-68 $\left({ }^{68} \mathrm{Ge}\right.$ ) isotope (a longlived radioisotope with $t_{1 / 2}=270.9 \mathrm{~d}$ ), which is produced by the proton bombardment of ${ }^{69} \mathrm{Ga}$, via a $\mathrm{p}, 2 \mathrm{n}$ nuclear reaction. ${ }^{67} \mathrm{Ga}$ citrate is used worldwide in the detection of tumors and infections in various inflammatory diseases. It also has the potential to become a therapeutic agent in the future due to the emission of Auger electrons.

${ }^{68} \mathrm{Ga}$ is currently produced using ${ }^{68} \mathrm{Ge} /{ }^{68} \mathrm{Ga}$ generator systems in the clinical and research environments. Current commercially available generators contain ${ }^{68} \mathrm{Ge}$ adsorbed onto a solid chromatographic support, although the first generator, "a positron cow" by Gleason, was based on a liquid/liquid extraction technique. ${ }^{7}$ Numerous researchers were involved in the development of ${ }^{68} \mathrm{Ge} /{ }^{68} \mathrm{Ga}$ generators with various solid supports, organic resins, ${ }^{8}$ and nano-zirconia and modified polymer solid support. ${ }^{9}$ Progress in the development of ${ }^{68} \mathrm{Ge} /{ }^{68} \mathrm{Ga}$ generators was slow after the late seventies due to (1) inadequate design of the generators, and (2) rapid development of new classes of ${ }^{99 \mathrm{~m}} \mathrm{Tc}$ and ${ }^{18} \mathrm{~F}$-labeled imaging pharmaceuticals.

However, the pioneering achievement of Russian radiochemists resulted in the development of a new ${ }^{68} \mathrm{Ge} /{ }^{68} \mathrm{Ga}$ generator, which became commercially available in the early years of the 21 st century. Since then, several ${ }^{68} \mathrm{Ge} /$ ${ }^{68} \mathrm{Ga}$ generators have become available for research and the manufacture of clinical-grade imaging pharmaceuticals. For example, titanium dioxide-based IGG100 (Eckert \& Ziegler), Galli EO (IRE Elit), Obninsk (Cyclotron Co. Ltd.), tin dioxide-based iThemba (iThemba Labs), and dodecyl gallate-modified silica-based ITG (ITG) are supplied for research use. Two $\mathrm{TiO}_{2}$-based ${ }^{68} \mathrm{Ge} /{ }^{68} \mathrm{Ga}$ generators, Gallia Pharm (Eckert \& Ziegler) and Galli Ad (IRE Elit) with open drug master files with the Food and Drug Administration (FDA) are available for human clinical use. The eluted $\left[{ }^{68} \mathrm{Ga}\right] \mathrm{GaCl}_{3}$, from these generators, meets European Pharmacopeia's specifications. The commercial generators are supplied with $10-100 \mathrm{mCi}$ capacity, have very low ${ }^{68} \mathrm{Ge}$-breakthrough $(<0.001 \%-0.005 \%$ depending on the supplier), very low metal/chemical impurities, and are eluted with $0.05-0.6 \mathrm{M} \mathrm{HCl}$. Claimed elution yields and shelf-lives are $60 \%-80 \%$ and 6-12 months or $250-400$ elutions, respectively. ${ }^{10,11}$ Fifty and ninety percent of ${ }^{68} \mathrm{Ga}$ radioactivity is regenerated in $68 \mathrm{~min}$ and $4 \mathrm{~h}$, respectively, for the next elution of the generator. The cost of the generators is high and varies depending on the supplier and/or the grade. Until recently, the supply of ${ }^{68} \mathrm{Ge} /{ }^{68} \mathrm{Ga}$ generators, specifically the good manufacturing practices (GMP) grade, had a long lead time to acquire (up to 18 months). Recently, the situation related to the supply of ${ }^{68} \mathrm{Ga}$ generators has improved (lead time being $\sim 3$ months) due to the availability of an alternate supplier for a GMP-grade generator and increased production capacity of the original supplier. It is anticipated that there may be ${ }^{68} \mathrm{Ge} /{ }^{68} \mathrm{Ga}$ generator production and supply issues again in the future when there will be increasing demand for PET imaging, particularly when PSMA imaging agents are approved and become reimbursable.

Production of ${ }^{68} \mathrm{Ga}$ radionuclide using cyclotrons has been proposed by the researchers as an alternative to ${ }^{68} \mathrm{Ge} /{ }^{68} \mathrm{Ga}$ generators due to (1) limited supply of ${ }^{68} \mathrm{Ga}$ each day, (2) the recurring replacement cost per year due to a shelf-life of 9-12 months, (3) the challenging and expensive disposal of radioactive waste of spent generators, which creates a need for long-term storage, and (4) high price of the generators is due to limited supply of ${ }^{68} \mathrm{Ge}$. ${ }^{68} \mathrm{Ge}$ can be produced in a high-energy accelerator using a variety of potential nuclear reactions. Some of the potential nuclear reactions are ${ }^{69} \mathrm{Ga}(\mathrm{p}, 2 \mathrm{n}){ }^{68} \mathrm{Ge},{ }^{\text {nat }} \mathrm{Ga}(\mathrm{p}, \mathrm{xn}){ }^{68} \mathrm{Ge}$ where $x=2$ and 4 , ${ }^{\text {nat }} \mathrm{Ge}(\mathrm{p}, \mathrm{pxn}){ }^{68} \mathrm{Ge},{ }^{69} \mathrm{Ga}(\mathrm{d}, 3 \mathrm{n}){ }^{68} \mathrm{Ge}$, ${ }^{66} \mathrm{Zn}(\alpha, 2 \mathrm{n}){ }^{68} \mathrm{Ge}$, and ${ }^{66,67,68} \mathrm{Zn}\left({ }^{3} \mathrm{He}, \mathrm{xn}\right){ }^{68} \mathrm{Ge}$ where $x=1-3$. There are a limited number of worldwide sites (Cyclotron Co., iThemba Laboratories, Brookhaven National Laboratory, Los Alamos National Laboratory, Institute of Nuclear Physics, Institute for Nuclear Research, and Orsay) for production of ${ }^{68} \mathrm{Ge} .{ }^{68} \mathrm{Ge}$ is currently being produced by $60-640$-h-long proton $(20$ to $\sim 60 \mathrm{MeV}$ energy and $40-125 \mu \mathrm{A}$ current) bombardment of Ga targets on various metallic backings. Typical yields are in the 9.2-32 $\mathrm{Ci} / \mathrm{Ah}$ range. ${ }^{12}$

Proton bombardment of enriched ${ }^{68} \mathrm{Zn}$ target by a cyclotron produces ${ }^{68} \mathrm{Ga}$ by the ${ }^{68} \mathrm{Zn}(\mathrm{p}, \mathrm{n}){ }^{68} \mathrm{Ga}$ nuclear reaction in the 11-14 MeV energy range. For high-purity ${ }^{68} \mathrm{Ga}$ production, the proton beam energy must be optimized due to the threshold energy for producing ${ }^{67} \mathrm{Ga}$ from competing ${ }^{68} \mathrm{Zn}(\mathrm{p}, 2 \mathrm{n}){ }^{67} \mathrm{Ga}$ reaction being $12 \mathrm{MeV}$.

The pioneering work $^{13}$ involving $\sim 14 \mathrm{MeV}$ and $20 \mu \mathrm{A}$ proton irradiation of $1.7 \mathrm{M}$ solution of ${ }^{68}$ Zinc nitrate in $0.2 \mathrm{~N}$ nitric acid, in a liquid target, for $30 \mathrm{~min}$, followed by cationexchange column purification produced $1.925 \mathrm{GBq}{ }^{68} \mathrm{Ga}$ with 5.20-6.27 GBq/ $\mu$ g molar activity. Furthermore, a $45 \mu \mathrm{A}$ proton beam energy irradiation of $30 \mathrm{mg} / \mathrm{mL}{ }^{68} \mathrm{Zn}\left(\mathrm{NO}_{3}\right)_{2}$ solution for $45 \mathrm{~min}$ yielded $6 \mathrm{GBq}$ of ${ }^{68} \mathrm{Ga}$. A production of $40 \mathrm{GBq}$ of ${ }^{68} \mathrm{Ga}$ was anticipated by optimization of concentration and beam parameters. ${ }^{14}$ The highest cyclotron production yield of ${ }^{68} \mathrm{Ga}(9.85 \mathrm{GBq})$ was achieved by $60 \mathrm{~min}$ of $45 \mu \mathrm{A}$ proton beam energy irradiation of $1.42 \mathrm{M}$ ${ }^{68} \mathrm{Zn}\left(\mathrm{NO}_{3}\right)_{2}$ solution in $1.42 \mathrm{M} \mathrm{HNO}_{3},{ }^{15}$ although some studies have shown limited production of $2.5-4.3 \mathrm{GBq}$ ${ }^{68} \mathrm{Ga} \cdot{ }^{16,17}$

Numerous studies involving electrodeposited ${ }^{68} \mathrm{Zn}$ on copper, platinum, and silver targets have been reported in the past. ${ }^{18-22}$ The targets were irradiated by protons at $30-150 \mu \mathrm{A}$ current and $12-15 \mathrm{MeV}$ incident beam energy. It was reported in 2009 that up to $189 \mathrm{GBq}$ of ${ }^{68} \mathrm{Ga}$ (end of beam, EOB) can be produced by $150 \mu \mathrm{A}$ 
Table 1. Comparison of MaXimum Radioactivity Produced by ${ }^{68} \mathrm{Ge} /{ }^{68} \mathrm{Ga}$ Generators AND By CyClotrons USING LIQUID AND SOLID TARgETS

\begin{tabular}{lc}
\hline Method & $\begin{array}{c}\text { Maximum amount } \\
\text { of radioactivity } \\
\text { produced, } G B q\end{array}$ \\
\hline${ }^{68} \mathrm{Ge} /{ }^{68} \mathrm{Ga}$ generators & 2.7 \\
Cyclotron using liquid target & 9.85 \\
Cyclotron using solid target & 194 \\
\hline
\end{tabular}

current and $15 \mathrm{MeV}$ energy proton beam bombardment of ${ }^{68} \mathrm{Zn}$ electrodeposited on copper target for $0.25 \mathrm{~h} .{ }^{18}$ Lower amounts of ${ }^{68} \mathrm{Ga}, 6.3-60.9 \mathrm{GBq}$ (EOB), were produced by irradiating ${ }^{68} \mathrm{Zn} /$ platinum targets with $30-35 \mu \mathrm{A}$ current and $14.5 \mathrm{MeV}$ energy beam for 8.5 to $60 \mathrm{~min} .{ }^{20,21}$ More recent studies used ${ }^{68} \mathrm{Zn}$ deposited on silver targets and an ARTMS Quantum irradiation system for the production of ${ }^{68} \mathrm{Ga}$. The EOB ${ }^{68} \mathrm{Ga}$ and end of separation (EOS) $\left[{ }^{68} \mathrm{Ga}\right] \mathrm{GaCl}_{3}$ yields exceeded 140 and $70 \mathrm{GBq}$, respectively, when the target was irradiated for 105 min with $40 \mu \mathrm{A}$ current and $13 \mathrm{MeV}$ energy beam, leading to the production of curie quantities of the ${ }^{68} \mathrm{Ga}$-labeled HBEDCC. ${ }^{21} \mathrm{~A}$ most recent study, under similar conditions except increasing the beam current to $80 \mu \mathrm{A}$ and irradiation time to $120 \mathrm{~min}$ led to the production of increased amounts of ${ }^{68} \mathrm{Ga},>370 \mathrm{GBq}$ (EOB) and $194 \mathrm{GBq}$ (EOS).

From the results presented above, as expected, it can be concluded that solid targets produce higher amounts of ${ }^{68} \mathrm{Ga}$ than liquid targets. On the contrary, the ${ }^{68} \mathrm{Ge} /{ }^{68} \mathrm{Ga}$ generators produce a limited amount of radioactivity, typically 2.7 $\mathrm{GBq}^{68} \mathrm{Ga}$ per elution, and they are successfully used in the clinical environment. Multiple elutions per day are possible from the generators providing additional amounts of radioactivity and improved radionuclide quality. A comparison of maximum radioactivity produced by the three methods is given in Table 1.

While ${ }^{68} \mathrm{Ge} /{ }^{68} \mathrm{Ga}$ generators are successfully being used in the clinical environment, for example, the use of a generator for radiolabeling of imaging tracers such as DOTA-TATE is now simple and requires a relatively inexpensive automatic synthesizer and a shielded hood. However, each generator can only produce a sufficient amount of ${ }^{68} \mathrm{Ga}$ each day for a limited number of patients. For a larger patient population, cyclotron production of ${ }^{68} \mathrm{Ga}$, using a solid or a liquid target, is a more attractive choice, which requires (1) a major capital investment in the cyclotron facility or availability of spare capacity in the existing facility, (2) working with complex targets, (3) the need for enriched material, (4) development of rapid, reliable, and robust processes, (4) the need for purification steps before the final radiolabeling step, and (4) the approval by the regulatory agencies. The major advantage of cyclotrom methods is that no Ge breakthrough exists. In summary, the three ${ }^{68} \mathrm{Ga}$ production methods are important, however, the choices between the three methods in the clinical environment can be made based on the patient needs, available resources, and the regulatory status of the method.

\section{Disclosure Statement}

The author has no personal interest in the commercial suppliers of ${ }^{68} \mathrm{Ge} /{ }^{68} \mathrm{Ga}$ generators or ${ }^{68} \mathrm{Ga}$-labeled-imaging pharmaceuticals.

\section{Funding Information}

This work was supported by the Ohio Third Frontier, TECH 13-060 and TECH 09-028 grants, and the Wright Center of Innovation Development Fund.

\section{References}

1. Afshar-Oromieh A, Holland-Letz T, Giesel FL, et al. Diagnostic performance of ${ }^{68}$ Ga-PSMA-11 (HBED-CC) PET/CT in patients with recurrent prostate cancer: Evaluation in 1007 patients. Eur J Nucl Med Mol Imag 2017; 44:1258.

2. Afshar-Oromieh A, Hetzheim H, Kratochwil C, et al. The theranostic PSMA ligand PSMA-617 in the diagnosis of prostate cancer by PET/CT: Biodistribution in humans, radiation dosimetry, and first evaluation of tumor lesions. J Nucl Med 2015;56:1697.

3. Ball P. The Ingredients: A Guided Tour of Elements. New York: Oxford University Press, 2002;105.

4. de Boisbaudran L. Caractères chimiques et spectroscopiques d'un nouveau métal, le gallium, découvert dans une blende de la mine de Pierrefitte, vallée d'Argelès (Pyrénées). C R Acad Hebd Seances Acad Sci 1835-1965; 81:493.

5. Wadas TJ, Wong EH, Weisman GR, et al. Coordinating radiometals of copper, gallium, indium, yttrium, and zirconium for PET and SPECT imaging of disease. Chem Rev 2010;110:2858.

6. Synowiecki MA, Perk LR, Nijsen JFW. Production of novel diagnostic radionuclide in small medical cyclotrons. EJNMMI Radiopharm Chem 2018;3:3.

7. Gleason GI. A positron cow. Int J Appl Rad Isot 1960;8: 90.

8. Rosch F. Past, present and future of ${ }^{68} \mathrm{Ge} /{ }^{68} \mathrm{Ga}$ generators. Appl Rad Isot 2013;76:24.

9. Chakravarty R, Shukla R, Ram R, et al. Development of nano-zirconia based $68 \mathrm{Ge} / 68 \mathrm{Ga}$ generator for biomedical applications. Nucl Med Biol 201;38:575.

10. Velikyan I. ${ }^{68}$ Ga-based radiopharmaceuticals: Production and application relationship. Molecules 2015:20: 12913.

11. Dash A, Chakravarty R. Radionuclide generators: The prospect of availing PET radiotracers to meet current clinical needs and future research demands. Am J Nucl Med Mol Imag 2019;9:30.

12. Roesch F, Filosofov DV. Production, radiochemical processing and quality evaluation of 68Ge. In: Production of Long Lived Parent Radionuclides for Generators: 68Ge, $82 \mathrm{Sr}, 90 \mathrm{Sr}$ and 188W, IAEA Radioisotopes and Radiopharmaceuticals Series No. 2, 2010; 11.

13. Pandey MK, Byrne JF, Jiang H, et al. Cyclotron production of ${ }^{68} \mathrm{Ga}$ via the ${ }^{68} \mathrm{Zn}(\mathrm{p}, \mathrm{n})^{68} \mathrm{Ga}$ reaction in aqueous solution. Am J Nucl Med Mol Imag 2014;4:303.

14. Alves F, Alves VHP, Do Carmo SJV, et al. Production of copper-64 and gallium-68 with a medical cyclotron using liquid targets. Modern Phys Let 2017;32:1740013-1. 
15. Pandey MK, Byrne JF, Schlasner KN, et al. Cyclotron production of ${ }^{68} \mathrm{Ga}$ in liquid target: Effects of solution composition and irradiation parameters. Nucl Med Biol 2019;74-75:49.

16. Nair M, Happel S, Eriksson T, et al. Cyclotron production and automated new 2-column processing of $\left[{ }^{68} \mathrm{Ga} \mathrm{Cl}_{3}\right.$. Eur J Nucl Med Mol Imag 2017;44(Suppl. 2): S119.

17. Stefano R, Cicoria G, Pancaldi D, et al. Production of Ga-68 with general electric PETtrace cyclotron by liquid target. Phys Med 2018;55:116.

18. Sadeghi M, Kakavand T, Rajabifar S, et al. Cyclotron production of ${ }^{68} \mathrm{Ga}$ via proton-induced reaction on $68 \mathrm{Zn}$ target. Nukleonika 2009;54:25.
19. Tieu W, Hollis CA, Kuan KKW, et al. Rapid and automated production of $\left[{ }^{68} \mathrm{Ga}\right]$ gallium chloride and $\left[{ }^{68} \mathrm{Ga}\right] \mathrm{Ga}-$ DOTA-TATE on a medical cyclotron. Nucl Med Biol 2019;74-75:12.

20. Lin M, Waligorski GJ, Lepera CG. Production of curie quantities of ${ }^{68} \mathrm{Ga}$ with medical cyclotron via the ${ }^{68} \mathrm{Zn}$ $(\mathrm{p}, \mathrm{n})^{68} \mathrm{Ga}$ reaction. Appl Rad Isot 2018;133:1.

21. Schweinsberg C, Johayem A, Llamazares A, et al. The first curie-quantity production of $\left[{ }^{68}\right]$ Ga-PSMA-HBED-CC. J Label Compd Radiopharm 2019, Poster-121; DOI: 10.1002/JLCR.3725.

22. Kumlin J, Dam JH, Chua CJ, et al. Multi curie production of gallium-68 on a biomedical cyclotron. Eur J Nucl Med Mol Imag 2019;46(Suppl. 1):S39. 